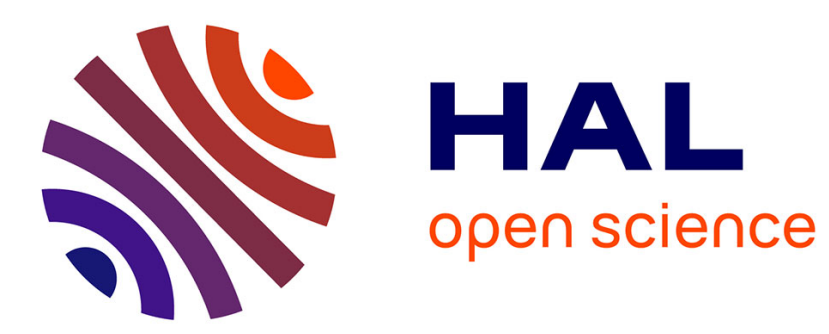

\title{
Maintenance policy optimisation for multi-component systems considering degradation of components and imperfect maintenance actions
}

\author{
Ronald Martinod, Olivier Bistorin, Leonel F Castaneda, Nidhal Rezg
}

\section{- To cite this version:}

Ronald Martinod, Olivier Bistorin, Leonel F Castaneda, Nidhal Rezg. Maintenance policy optimisation for multi-component systems considering degradation of components and imperfect maintenance actions. Computers \& Industrial Engineering, 2018, 124, pp.100-112. 10.1016/j.cie.2018.07.019 . hal-02144554

\section{HAL Id: hal-02144554 \\ https://hal.science/hal-02144554}

Submitted on 30 May 2019

HAL is a multi-disciplinary open access archive for the deposit and dissemination of scientific research documents, whether they are published or not. The documents may come from teaching and research institutions in France or abroad, or from public or private research centers.
L'archive ouverte pluridisciplinaire HAL, est destinée au dépôt et à la diffusion de documents scientifiques de niveau recherche, publiés ou non, émanant des établissements d'enseignement et de recherche français ou étrangers, des laboratoires publics ou privés. 


\title{
Maintenance policy optimisation for multi-component systems considering degradation of components and imperfect maintenance actions
}

\author{
Ronald M. Martinod $^{\mathrm{a}, *,}$, Olivier Bistorin ${ }^{\mathrm{b}}$, , Leonel F. Castañeda ${ }^{\mathrm{a}}$, Nidhal Rezg ${ }^{\mathrm{c}}$ \\ ${ }^{a}$ Universidad EAFIT, Department of Mechanical Engineering, Engineering School, Carrera 49 Nr. 7 Sur-50, Medellín, Colombia \\ ${ }^{\mathrm{b}}$ ICN Business School Nancy Metz, Dpt. Management de la Supply Chain et des Systèmes d'information, 3, place Edouard Branly, 57070 Metz Technopôle, Metz, France \\ ${ }^{\mathrm{c}}$ Université de Lorraine, Laboratoire de Génie Industriel de Production et de Maintenance (LGIPM), College of Mathematics, Information, Mechanics and Automatics, Ile du Saulcy, 57045 Metz \\ Cedex, Metz, France
}

\section{ARTICLE INFO}

\section{Keywords:}

Maintenance optimisation

Maintenance policy

Multi-component system

Urban ropeway transport

\begin{abstract}
A B S T R A C T
This article proposes a stochastic optimisation model in order to reduce the long-term total maintenance cost of complex systems. The proposed work is based on the following approaches: (i) optimisation of a cost model for complex multi-component systems consisting of preventive and corrective maintenance using reliability analysis, which faces two different maintenance policies (periodic block-type and age-based) and (ii) a clustering method for maintenance actions to decrease the total maintenance cost of the complex system. This work evaluates each maintenance policy and measures the effects on imperfect maintenance actions. Finally, the proposed optimisation model is applied to a numerical example which focuses on passenger urban aerial ropeway transport systems, in which the current maintenance policy has been evaluated, considering the established by the international regulation of passenger aerial cable cars.
\end{abstract}

\section{Introduction}

Traditional optimisation models based on maintenance of complex systems have been considered as a collection of independent components (Chelbi \& Ait-Kadi, 2001; Cho \& Parlar, 1991; Yang, Ma, Peng, Zhai, \& Zhao, 2017); nevertheless, taking account the complexities involved in engineering systems and the need to improve the maintenance activities, it is no longer sensible to treat each component in such systems as an individual component (Cheng, Zhou, \& Li, 2017). The maintenance resources of an engineering system - production and service as well - can be reduced if a set of components are repaired using only one type of maintenance action (Peng \& Zhu, 2017).

There are models (Briš \& Byczanski, 2013; Gustavsson, Patriksson, Strömberg, Wojciechowski, \& Önnheim, 2014) based on dependencies between the components in a complex system; these dependencies lead to further problems to understand the behaviour of the system (Briš, Byczanski, Goňo, \& Rusek, 2017). The dependence-based models have assumed that all components in the system belong to a certain group according to an a-priori classification based on a deterministic criterion - e.g. the components are grouped by similarities of the shape, functionality, assembly or location within the system. Some studies of dependence-based models have been focused on the optimal maintenance policies for a multi-component system (Ahmad \& Kamaruddin, 2012; Nicolai \& Dekker, 2008; Van Horenbeek \& Pintelon, 2013; Yang, Zhao, Peng, \& Ma, 2018), the set of the main dependencies are the following: (i) stochastic dependency, which considers the effect of the component deterioration regarding the lifetime distribution of others components, the studies in this area (Liu, Xu, Xie, \& Kuo, 2014; Yang et al., 2017) focus on the trigger effect by failure of a component - i.e. failure interactions; (ii) structural dependency (Iung, Do, Levrat, \& Voisin, 2016; Peng \& Zhu, 2017), which focuses on the assembly relationship condition of a component in a subsystem; and (iii) economic dependency (Do, Vu, Barros, \& Bérenguer, 2015; Qiu, Cui, Shen, \& Yang, 2017; Van Horenbeek and Pintelon, 2013; Zhou, Huang, Xi, \& Lee, 2015), which assumes that a maintenance action cost of a grouped component does not equal to the sum of the maintenance cost of all individual components.

The effect of the clustering techniques on maintenance costs have been considered for a reduced set of systems with specific configurations (Wang, Tsai \& Li, 2011). Yang, Djurdjanovic and Ni (2008) used a dependence-based model to develop a maintenance schedule based on the expected degradation of the machine by taking into account the complex interaction between the components, the production process, and the maintenance operations. Later, Tian and Liao (2011) proposed a maintenance policy based on a proportional hazard model for multi-component systems, and a policy was established for

\footnotetext{
* Corresponding authors.

Email addresses: rmartino@eafit.edu.co (R.M. Martinod); olivier.bistorin@icn-groupe.fr (O. Bistorin); lcasta@eafit.edu.co (L.F. Castañeda); Nidhal.rezg@univ-lorraine.fr (N. Rezg)
} 
placements of spare parts. Subsequently, Liu et al. (2014) formulated a preventive maintenance policy for multi-component systems concerning continuously degrading components. In addition, Zhou et al. (2015) proposed a time window based preventive maintenance model for multi-component systems with stochastic failures and the disassembly sequence involved. Nevertheless, it is possible to identify that the literature has not reported dependence-based models without a pre-established classification (shape, functionality, assembly, etc.), which combines the reliability analysis of the complex systems and the working-life condition of each component.

Other models (Do et al., 2015; Iung et al., 2016; Martinod, Bistorin \& Rezg, 2018) have assumed that all members of a group have identical behaviour (i.e. identical working rate, wear ratio, degradation, etc.); therefore, these models are based on hypotheses with simplifications; thus, these models are limited because they do not consider that the same type of components in the system could: (i) come from different suppliers with different quality; (ii) come from different production batches; (iii) have a material quality variation; (iv) have a metrological variation; (v) have different working stress; and (vi) have different working environment. This work shows that it is possible to develop a maintenance policy model which considers a multi-component system affected by multiple types of independent degradation processes. Economic dependencies are common in most continuous operating systems, such as aircrafts, powerplants, or chemical processing facilities. This work focuses on economic dependencies, it means a conjoined maintenance action can yield a lower total cost than maintaining each component separately.

An efficient maintenance policy should consider a long-time period between preventive maintenance actions. Nevertheless, under operational conditions, increasing the period between preventive maintenance actions decreases the reliability function of each component; thus, increasing the maintenance cost by increasing the corrective maintenance actions (Qiu et al., 2017; Yang et al., 2017). If non-identical components are considered in a complex multi-component system, each single component will have different reliability function and a different period between preventive maintenance as well. In this article, an optimisation of maintenance policy process is developed for multi-component systems, where a reliability relationship is considered among different components subjected to each single condition during their working-life. Given a multi-component system comprised of sets with the same type of components, wherein the components are not necessarily identical, and these components may even have: (i) variation of properties, e.g. material quality or metrological variation; (ii) working rate variation due to different operation conditions of the system; and (iii) independent degradation processes. The objective is to minimise the long-term maintenance action cost of complex systems. Main contributions of the article can be summarised as follows:

(i) a dependence-based optimisation model and different maintenance policies (periodic block-type and age-based) are merged to solve the problem of maintenance in complex systems considering the imperfect maintenance actions;

(ii) a stochastic optimisation is developed in order to provide a maintenance plan accounting for the degradation process of each element in a multi-component system; and

(iii) a method to cluster the maintenance actions is proposed in order to reduce the long-term total maintenance cost of complex systems, evaluating how imperfect maintenance actions influence the system.

The concept that maintenance actions reduce the age of the system is based on Kijima's virtual age models (1989), in which the reduction of age model has a failure intensity that is a function of its virtual age. Usually, studies on repairable systems (Ahmadi, Soleimanmeigouni, Block, \& Letot, 2016; Doyen \& Gaudoin, 2004; Yang et al., 2017) mainly focus on reliability models with a single component under different maintenance actions defined by conditional distributions of suc- cessive inter-failures in terms of time. Nonetheless, this study will consider multi-component systems with non-identical components, which follow fault probability distributions within their frequency domain. This article is organised as follows: Section 2 exposes the mathematical expressions of the problem description. Section 3 develops an optimisation model for complex multi-component systems that consider the degradation of components for obtaining the optimal maintenance actions. The model is applied in Section 4 by means of a numerical example that focuses on an urban public ropeway system and this section also proposes analyses of the results and a discussion of the work. Finally, Section 5 offers a conclusion and draws some perspectives of this work.

Table 1 presents the coefficients, parameters, and variables which will be used throughout this article.

Table 1

Indices and parameters used throughout the paper.

\begin{tabular}{|c|c|}
\hline$i$ & Intant of lifetime \\
\hline$j=\{1,2, \ldots, J\}$ & Indices of the components on the system \\
\hline$k=\{1,2, \ldots, K\}$ & Indices of clustered preventive maintenance actions \\
\hline$\eta$ & Horizon of time, long-term window of lifetime \\
\hline$B_{k}$ & Bernstein polynomial \\
\hline $\mathscr{F}_{h}$ & Parametric curve proposed by De Casterljeau \\
\hline$g$ & Piecewise-defined parametric curve \\
\hline$u$ & Parameter of the parametric curve $\mathscr{F}_{h}$ \\
\hline$P(\cdot)$ & Probability function \\
\hline \multicolumn{2}{|c|}{ Maintenance policy parameters: } \\
\hline$\alpha_{j, \eta}$ & $\begin{array}{l}\text { Age reduction coefficient after a maintenance action of the } j \\
\text { th component, over the } \eta \text { period of lifetime, } \alpha_{j, \eta}=\left\{\alpha_{p 1}, \alpha_{p 2}\right\}\end{array}$ \\
\hline$\alpha_{p 1}, \alpha_{p 2}$ & $\begin{array}{l}\text { Age reduction after a major and minor preventive } \\
\text { maintenance action, respectively }\end{array}$ \\
\hline$\beta_{j, \eta}$ & $\begin{array}{l}\text { Stochastic hazard rate of the } j \text { th component and over the } \eta \\
\text { period of lifetime, related to a human and technical } \\
\text { uncertainty of a maintenance action }\end{array}$ \\
\hline$p$ & $\begin{array}{l}\text { Relationship between the quantity of minor maintenance } \\
\text { actions per each major maintenance action }\end{array}$ \\
\hline$f_{j}, F_{j}$ & $\begin{array}{l}\text { Probability and cumulative fault distribution of the } j \text { th } \\
\text { component [cycles], respectively }\end{array}$ \\
\hline$R_{j}, \Delta R_{j, \eta}$ & $\begin{array}{l}\text { Reliability probability function and reliability gain of the } j \text { th } \\
\text { component [cycles], respectively }\end{array}$ \\
\hline$R_{\text {inf }}$ & Lower threshold of the reliability function [cycles] \\
\hline$\omega_{j}, \omega_{o}, \omega_{A}$ & $\begin{array}{l}\text { Current working cycles, working cycles of the last } \\
\text { maintenance action and working cycles of the next } \\
\text { maintenance action of the jth component [cycles], } \\
\text { respectively }\end{array}$ \\
\hline$\varphi_{j, \eta}$ & $\begin{array}{l}\text { Failure probability average of the } \mathrm{j} \text { th component over the } \\
\text { finite period of time } \tau\end{array}$ \\
\hline$\tau$ & $\begin{array}{l}\text { Period of time between preventive maintenance actions } \\
\text { [year/maint.] }\end{array}$ \\
\hline \multicolumn{2}{|c|}{ Optimisation parameters: } \\
\hline$C p_{j}$ & $\begin{array}{l}\text { Cost of a perfect maintenance action (AGAN) to the } j \text { th } \\
\text { component, which is quantified on monetary unit (mu) per } \\
\text { maintenance action [mu/maint.] }\end{array}$ \\
\hline$C c_{j}$ & $\begin{array}{l}\text { Cost of a corrective maintenance action to the } j \text { th } \\
\text { component, which is related to the cost of the time-dead of } \\
\text { the system, the cost of logistic actions, labour cost, cost of } \\
\text { devices and equipment [mu/maint.] }\end{array}$ \\
\hline$C_{1}, C_{2}$ & $\begin{array}{l}\text { Cost of the major and minor preventive maintenance action } \\
{[\mathrm{mu} / \text { maint.], respectively }}\end{array}$ \\
\hline$C_{j, \eta}$ & $\begin{array}{l}\text { Optimisation function of maintenance cost to the } j \text { th } \\
\text { component [mu/year] }\end{array}$ \\
\hline$C_{j, \eta}^{*}$ & Optimal maintenance cost value of $C_{j, \eta}[\mathrm{mu} /$ year $]$ \\
\hline$C_{k}^{* *}$ & $\begin{array}{l}\text { Opportunistic cost of the optimal period } C_{j, \eta}^{*} \text { by clustering } \\
\text { [mu/year] }\end{array}$ \\
\hline$e_{k}$ & $k$ th cluster centre of a set of maintenance actions \\
\hline E & Objective function by k-means algorithm \\
\hline$\Gamma c_{j, \eta}, \Gamma p_{j, \eta}$ & $\begin{array}{l}\text { Cost of a corrective and a preventive maintenance of the } j \text { th } \\
\text { component [mu/year], respectively }\end{array}$ \\
\hline \multicolumn{2}{|l|}{ Decision variables: } \\
\hline$A_{j}$ & $\begin{array}{l}\text { Range of working cycles over the } j \text { th component based on } \\
\text { age-based preventive maintenances }\end{array}$ \\
\hline$T_{j}$ & $\begin{array}{l}\text { Periodicity over preventive maintenance actions } \\
\text { [maint./year] }\end{array}$ \\
\hline $\mathbb{T}_{k}$ & $\begin{array}{l}\text { Periodicity of the preventive maintenance actions of the } k \text { th } \\
\text { optimal period cluster [maint./year] }\end{array}$ \\
\hline
\end{tabular}




\section{Problem formulation}

This work considers the following assumptions regarding the multi-component systems under discussion: (i) a system with $j$ non-identical components, with $j=\{1,2, \ldots, J\}$; (ii) a failure process $f_{j}(\omega)$ for the $j$ th component, i.e. a fault probability distribution at frequency domain $\omega$, where $\omega>0$ - e.g. faults per working cycle; and (iii) a failure of the $j$ th component affecting the performance of the system. Let $F_{j}$ be the cumulative fault probability distribution function from $f_{j}(\omega)$, the reliability function of the $j$ th component in a system is $R_{j}(\omega)=1-F_{j}(\omega)$, where the nominal value is $R_{j}(0)=1$ (Yang et al., 2018).

Maintenance managements can adopt a different maintenance policy regarding the repairing actions. The repairing actions affect the technical state of the repaired component, i.e. considering a long-term horizon of lifetime, $\eta$, a series of repairing actions produce a reduction on the degradation level of the $j$ th component by a $\left(1-\alpha_{j, \eta}\right)$ factor, with $0 ? \alpha_{j, \eta}$ ?1 (Khatab, Ait-Kadi \& Rezg, 2013); these maintenance policies are usually executed from three cases (Qiu et al., 2017; Schutz \& Rezg, 2013; Van Horenbeek \& Pintelon, 2013; Yang et al., 2018):

(i) In the case that a maintenance management executes a maintenance action with a value $\alpha_{j, \eta}=0$, the reliability level takes the nominal value $R_{j}\left(\omega_{j}\right)=1$. This means that a perfect maintenance action - defined as-good-as-new (AGAN) - is performed, which consists in repairing the component using the required resources to get the highest quality reparation.

(ii) In the case that a maintenance management executes a maintenance action with a value $\alpha_{j, \eta}=1$, the reliability level remains as the value before the fault $R_{j}\left(\omega_{j}\right)$. This means that a minimal-maintenance action - defined as-bad-as-old (ABAO) - is performed.

(iii) In the case that a maintenance management executes a maintenance action with a value within the range $0<\alpha_{j, \eta}<1$, this means that an imperfect maintenance action is performed.

\subsection{Preventive maintenance policies}

Preventive maintenance has been introduced to minimise the effect of unscheduled breakdowns; it interferes in a planned manner by means of improving the $R_{j}$ level of the $j$ th component. Imperfect preventive maintenance is widely spread in the field of engineering and has been mainly adopted by the maintenance managements (Liu, Yeh \& Cai, 2017; Pham \& Wang, 1996; Qiu et al., 2017). Therefore, this work will focus on the imperfect preventive maintenance $\left(0<\alpha_{j, \eta}<1\right)$. After each preventive maintenance action, the equipment is restored to a lower level than the nominal state of its components, i.e. over the lifetime of the system its components undergo wear and degradation.

Let's define $C p_{j}$ as the cost of a perfect maintenance action, which is given in monetary units (mu), it will represent the cost of the required resources to get the highest quality maintenance and to restore the reliability function of the component to its nominal value, i.e. AGAN maintenance. As a consequence, when the budget of a maintenance action for the jth component is equivalent to its $C p_{j}$, the executed maintenance action is AGAN; hence, the value of the age reduction is $\alpha_{j, \eta}=0$, and it means that the $j$ th component has been replaced by new $j$ th spare part.

The proposed model assumes imperfect maintenance actions; thus, the maintenance action cost is a fraction of $C p_{j}$, which is directly related to the age reduction coefficient after a maintenance action; then, the preventive maintenance action can be expressed as $C p_{j}\left(1-\alpha_{j, \eta}\right)$. The preventive maintenance actions are classified in two types: a major maintenance and a minor maintenance. The age reduction coefficient before a preventive maintenance action is $\alpha_{j, \eta}=\left\{\alpha_{p 1}, \alpha_{p 2}\right\}$, where $\alpha_{p 1}$ and $\alpha_{p 2} \in\left(0<\alpha_{j, \eta} \leqslant 1\right)$, with $\alpha_{p 1}$ being the age reduction after the major maintenance action, and $\alpha_{p 2}$ being the age reduction coefficient after the minor maintenance. The relationship between the major and the minor preventive maintenance is defined by means of the parameter $p$ , which describes the quantity of minor maintenance actions per each major maintenance action.

Remark 1. Note that, the cost of the major maintenance action,

$C_{1}=C p_{j}\left(1-\alpha_{p 1}\right)$,

is higher than the cost of the minor maintenance action,

$C_{2}=C p_{j}\left(1-\alpha_{p 2}\right)$

thus, $C_{1}>C_{2}$ and $\alpha_{p 1}<\alpha_{p 2}$

The imperfect preventive maintenance actions produce the reliability gain, $\Delta R_{j, \eta}$, that is related to the inverted resource in the maintenance action by improving the coefficient $\left(1-\alpha_{j, \eta}\right)$ (e.g. an annual maintenance action demands a higher cost than a quarterly maintenance action, in consequence, an annual maintenance action must increase the reliability gain more than a quarterly maintenance action).

In fact, $\Delta R_{j, \eta}$ is affected by two factors:

(i) a tactical factor: factor related to the general conditions of the maintenance action - e.g. the type of preventive maintenance - that relies on $\alpha_{j, \eta}$, which quantifies the fraction of $C p_{j}$ that the maintenance manager has available for the preventive maintenance action; and

(ii) an operational factor: which quantifies the quality of the operative action applied on the maintenance - e.g. the repairman's expertise, the technic, the technical support, and the quality and state of the used devices and tools. The value of the operational factor is defined through a hazard rate model $\beta_{j, \eta}$, where 0 ? $\beta_{j, \eta}$ ? 1 , then $\beta_{j, \eta}$ is a stochastic index of the $j$ th component and carries throughout $\eta$ , which is related to a human and technical uncertainty over the maintenance action.

Then, $\Delta R_{j, \eta}$ can be expressed in terms of the reliability function, the tactical factor, and the operational factor

$\Delta R_{j, \eta}=\beta_{j, \eta}\left(1-R_{j}\right)\left(1-\alpha_{j, \eta}\right)$,

with $\alpha_{j, \eta}=\left\{\alpha_{p 1}, \alpha_{p 2}\right\}$.

Remark 2. In the case that $\beta_{j, \eta}=1$, the preventive maintenance model becomes a single age reduction model, i.e. the imperfect maintenance cost is affected only by the tactical factor, and it means that the maintenance action was executed with an extreme quality procedure; therefore, the maintenance action was executed without the uncertainty factor; thus, Eq. (3) can be rewritten as $\Delta R_{j, \eta}=\alpha_{j, \eta} R_{j}-R_{j}-\alpha_{j, \eta}+1$.

Remark 3. This work assumes that the relationship between the preventive maintenance action cost (major and minor as well) and the efficiency of its maintenance action are described as a linear function, i.e. the $\Delta R_{j, \eta}$ value is lineally relied on the values of $C_{1}$ and $C_{2}$. The lineal function is adopted because it appropriately describes the cost-efficiency of maintenance actions for some technical systems. An evolution of this strong assumption will be part of future works, according to the correlations pointed by the literature review.

This work considers a model for both different preventive maintenance policies (periodic block-type and age-based), they are discussed in the following lines. 


\subsubsection{Periodic block-type policy}

The periodic block-type maintenance is performed periodically using maintenance actions during a long-term period over the lifetime, e.g. maintenance/year (Khatab, et al., 2013; Martinod et al., 2018). This policy accounts for a horizon of time expressed as $\eta$, with a piecewise linear distribution of time $T$, and an equally frequency of maintenance actions $\tau$ (see Fig. 1). Therefore, the periodicity condition of the periodic block-type policy is defined as

$\eta=\tau(1+p)$

Proposition 1. The weighted average cost for the jth component in the periodic block-type actions is expressed as

$\Gamma p_{j, \eta}=C p_{j} T_{j}\left(1-\frac{\alpha_{p 1}+p \alpha_{p 2}}{1+p}\right)$,

where $1+p$ is a full cycle of preventive maintenance over the long-term horizon of time $\eta$.

Proof 1 . By definition, the weighted average cost of the maintenance relies on the sum of the maintenance actions cost over the period of time that is performed

$\Gamma p_{j, \eta}=\left(\frac{1}{\tau}\right)\left(C_{1}+\sum_{p} C_{2}\right)$

then, taking Eqs. (1) and (2) into Eq. (6) with some algebraic manipulations

$\Gamma p_{j, \eta}=\left(\frac{1}{\tau}\right) C p_{j}\left(1+p-\alpha_{j, \eta}-p \alpha_{p 2}\right)$.

Using the periodicity condition of the periodic block-type policy expressed in Eq. (4) and taking it into Eq. (7), it can be expressed as

$\Gamma p_{j, \eta}=\left(\frac{1+p}{\eta}\right) C p_{j}\left(1-\frac{\alpha_{p 1}+p \alpha_{p 2}}{1+p}\right)$.

From the periodically maintenance actions over the long-term time, it is possible to say that $T_{j} \eta=1+p$, and taking into account this relationship into Eq. (8) the proposition is proved.

\subsubsection{Age-based policy}

The age-based policy is executed according to the value of the reliability function to each component (Wang, 2002; Yang et al., 2018), i.e. the system undergoes a preventive maintenance whenever its $R_{j}$ value reaches a given threshold level, $R_{\text {inf }}$. The quantity of the working cycles is considering according to the behaviour of each component in the operation of the system (see Fig. 2).

Proposition 2. The weighted average cost for the jth component in the age-based policy actions are the following

$\Gamma p_{j, \eta}=\frac{C p_{j}}{A_{j}}\left(1-\frac{\alpha_{p 1}+p \alpha_{p 2}}{p+1}\right)$,

where the $A_{j}$ value covers the working cycles executed by the system under working degradation between preventive maintenance actions.

Proof 2. By definition, the weighted average cost of the maintenance relies on the sum of the maintenance action cost under the working cycles that are performed

$\Gamma p_{j, \eta}=\left(\frac{1}{R_{j, \eta}^{-1}\left(R_{\mathrm{inf}}\right)-R_{j, \eta}^{-1}\left(R_{\omega o}\right)}\right)\left(C_{1}+\sum_{p} C_{2}\right)$,

where $R_{j, \eta}^{-1}(\cdot)$ expresses the inverse reliability function of the $j$ th component, and $R_{\omega o}$ is the reliability function level of the last preventive maintenance action.Taking Eqs. (1) and (2) into Eq. (10), and after some algebraic manipulations

$\Gamma p_{j, \eta}=\left(\frac{1}{R_{j, \eta}^{-1}\left(R_{\mathrm{inf}}\right)-R_{j, \eta}^{-1}\left(R_{\omega o}\right)}\right) C p_{j}\left(1+p-\alpha_{j, \eta}\right.$.

The $R_{\text {inf }}$ value can be expressed as $R_{\text {inf }}=R_{j, \eta}\left(\omega_{A}\right), \exists \omega_{A} \in \omega$; thus, $\omega_{A}=R_{j, \eta}^{-1}\left(R_{\text {inf }}\right)$, where $\omega_{A}$ is the quantity of working cycles in which the system reaches $R_{\text {inf. }}$. Besides, $R_{\omega o}=R_{j, \eta}\left(\omega_{o}\right)$ and $\omega_{o}=R_{j}^{-1}\left(R_{\omega o}\right)$. It follows Eq. (11) that

$\Gamma p_{j, \eta}=\left(\frac{1}{\omega_{A}-\omega_{o}}\right) C p_{j}\left(1-\frac{\alpha_{p 1}+p \alpha_{p 2}}{1+p}\right) ;$

then, for a given working cycles range $A_{j}=\omega_{A}-\omega_{o}$, taking into account this relationship into Eq. (12) the proposition is proved.

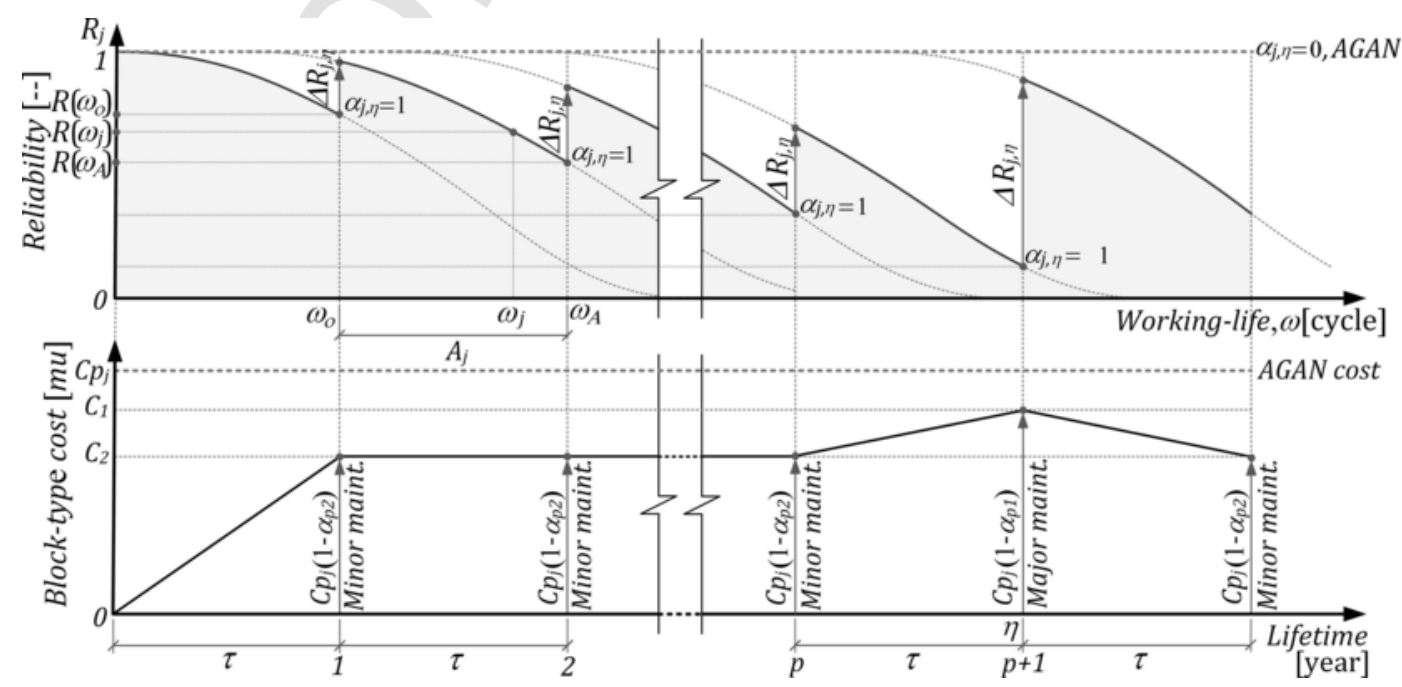

Fig. 1. Periodic block-type preventive maintenance of the $j$ th component. 


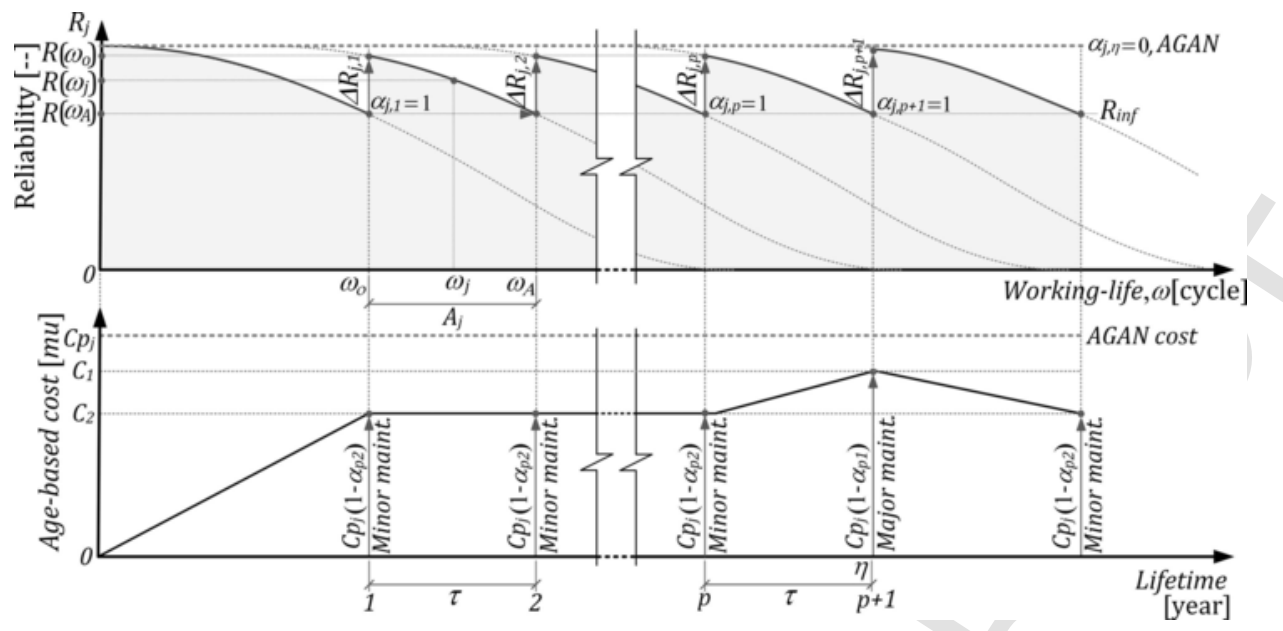

Fig. 2. Age-based preventive maintenance of the $j$ th component.

\subsection{Corrective maintenance policy}

The repairing action cost associated with the fault of the jth component is expressed as a unit cost value, $C c_{j}$, and the repairing actions of a failed component are executed between the scheduled preventive maintenances (Yang et al., 2017), i.e. between the working cycles range, $A_{j}$ (see Fig. 3).

Remark 4. The corrective maintenance policy, commonly used by the maintenance management, corresponds to the minimal-repair (Khatab, et al., 2013; Pham \& Wang, 1996). The minimal-repair action consists in restoring the system to the working state immediately before the failure. The minimal-repair action to a failed component is adopted by this work; thus, the proposed model adopts the ABAO corrective maintenance policy, which is defined by $\alpha_{j, \eta}=1$, i.e. $R_{j}$ remains unchanged to its value before the fault.

The corrective maintenance cost action, $\Gamma c_{j, \eta}$, is expressed as $C c_{j}$ and it is affected by the failure probability average, $\varphi_{j, \eta}$,

$\Gamma c_{j, \eta}=C c_{j} \varphi_{j, \eta}$

where $\varphi_{j, \eta}$ is the failure probability average for the $j$ th component over a finite period of time, considered from the current lifetime, $\omega_{j}$, to the next preventive maintenance action, $\omega_{A}$, with $\omega_{j}<\omega_{A}$.

\subsection{Proposed methodology framework}

For corrective maintenance, the repairmen action should be taken immediately after the failure of the component; the proposed methodology adopts an ABAO corrective maintenance policy. For preventive maintenance, the best periodicity of the maintenance action should be adopted to avoid a failure event, and avoid any corrective maintenance actions as well.
The proposed methodology is based on a system-dependent model for a long-term total maintenance cost, $C_{j, \eta}$; i.e., an economic dependence regarding to maintenance actions over the components of a technical system. The proposed methodology considers preventive and corrective maintenance actions which have a cost-based component, $\Gamma p_{j, \eta}$ and $\Gamma c_{j, \eta}$, respectively.

Remark 5. If $\tau$ increases, then $\Gamma p_{j, \eta}$ decreases, and as a result, the quantity of preventive actions decrease as well; but if $\tau$ increases, then $\left(\Gamma c_{j, \eta}\right)$ increases because the $R_{j, \eta}$ level decreases.

An optimisation process has been developed in the proposed methodology, the process of optimisation is structured in two stages (see Fig. 4): (i) a maintenance optimisation, based on the long-term total cost of corrective and preventive maintenance (the optimal value of each component establishes the periodicity of preventive maintenance actions, based on $R_{j, \eta}$ ); and (ii) a maintenance optimal cost of a multi-component system is determined by clustering the preventive maintenance actions of the multi-component system. This process of optimisation is further discussed in detail in Section 3.

A model has been developed in a virtual environment using a programming language that allows researching the effects of a wider range of condition and parameter variations. The model is defined by $F_{j}(\omega)$, which has been affected by the preventive and corrective maintenance actions. Therefore, the model has considered the effects of $\alpha_{j, \eta}$ and $\beta_{j, \eta}$ , where $\beta_{j, \eta}$ has an uniform distribution. This model has been subjected to a sensitivity analysis by means of 500 test sets, and each test covered $240 \mathrm{E} 3$ [cycles] of the components working-life, which comprises a three years period.

Appendix A (Fig. A.1) shows the sensitivity analysis performance of every $F_{j}(\omega)$. The set of functions $F_{j}(\omega)$ is used to describe the system's behaviour data during a working-life; therefore, a relationship can be established between a measure of central tendency - such as the average values, mean $\left(F_{j}(\omega)\right)$ - and a measure of dispersion - such as the de-

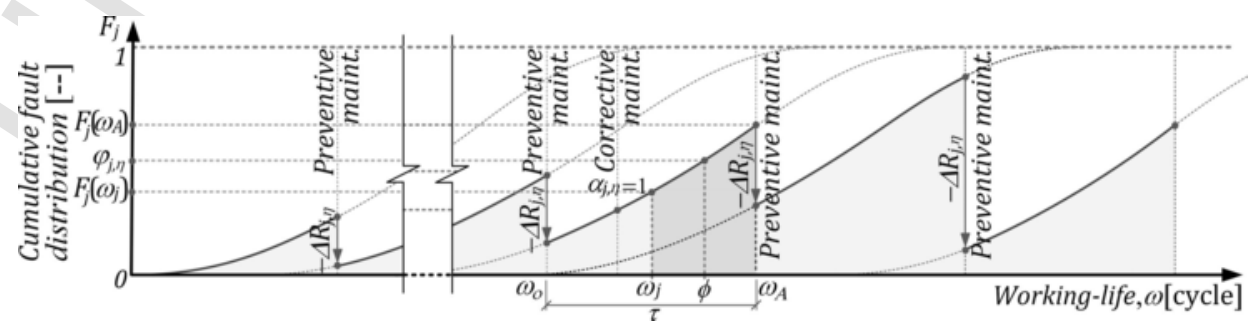

Fig. 3. Corrective maintenance policy parameters. 


$$
\begin{aligned}
& \text { Prolual:ali: laul } \\
& \therefore \text { ivil: } \\
& \text { ( i:1:ulis: : } \\
& \text { 13: } \because 2 \text { is } \\
& \text { lill: : }
\end{aligned}
$$

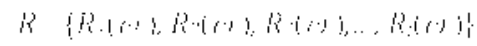

$$
\begin{aligned}
& \begin{array}{c}
3 \\
3 \\
\end{array}
\end{aligned}
$$

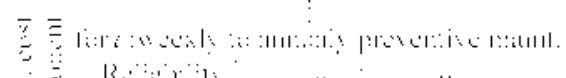

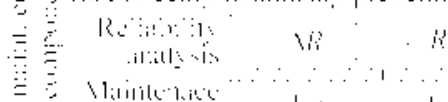

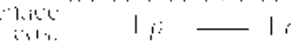

$$
\begin{aligned}
& \text { la:ilian }
\end{aligned}
$$

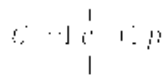

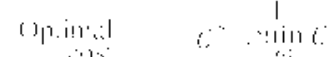

$$
\begin{aligned}
& \text { prisis } \\
& \therefore \cdots
\end{aligned}
$$

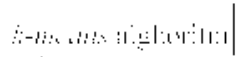

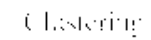

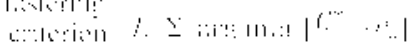

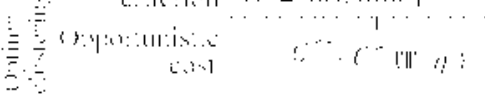

Fig. 4. Flow diagram of the proposed methodology.

viation standard, $\operatorname{std}\left(F_{j}(\omega)\right)$ - to quantify the sensitivity of the model regarding the lifetime. The value of $\operatorname{st} d\left(F_{j}(\omega)\right)$ to each maintenance action had an acceptable deviation level for the scope of this work $(<0.85 \%)$.

The model is subjected to a convergence analysis to quantify the required simulations in order to reach a stable value, Appendix A (Fig. A.2) shows the results of $F_{j}(\omega)$ at three years of lifetime; therefore, a total of 73 simulations are necessary to fulfil the requirements, wherein a value lesser than $3 \%$ of variation represents an acceptable deviation level for this study.

\section{Optimisation process}

This work introduces a stochastic optimisation model in order to prove a multi-component maintenance plan. The optimal service plan is obtained by minimising the expected long-term cost for the maintenance activities. A cost-based model is proposed to quantify the involved resources in the maintenance policies. The optimisation process is structured in two stages:

\subsection{Optimisation of maintenance actions cost to each component}

The $j$ th component requires a maintenance protocol for its working lifetime in the technical system, which is executed by means of a set of maintenance actions (Yang et al., 2018); thus, incurring in long-term maintenance costs, $\Gamma p_{j, \eta}$ and $\Gamma c_{j, \eta}$. Note that $\Gamma c_{j, \eta}$ increases as the level of $\tau$ increases, and on the other hand, $\Gamma p_{j, \eta}$ increases while decreasing $\tau$ . Formally, the maintenance total cost is defined as follows

$C_{j, \eta}=C c_{j} \varphi_{j, \eta}+C p_{j} \mathbb{M}\left(1-\frac{\alpha_{p 1}+p \alpha_{p 2}}{p+1}\right)$,

where $\mathbb{M}=\left\{T_{j}, A_{j}^{-1}\right\}$ represents the decision variables, with $\mathbb{M}=T_{j}$ if the periodic block-type maintenance policy is considered, and $\mathbb{M}=A_{j}^{-1}$ if the age-based maintenance policy is considered. Therefore, the objective function related to the maintenance policy cost can be expressed as

$C_{j, \eta}^{*}=\min _{\omega} C_{j, \eta}$

subject to the following constraints

$0 \leqslant R_{j}(\omega)+\Delta R_{j, \eta} \leqslant 1, \quad \forall j, \eta$
$0 \leqslant F_{j}(\omega)-\Delta R_{j, \eta} \leqslant 1, \quad \forall j, \eta$

$R g_{\text {inf }} \leqslant R_{j}(\omega) \leqslant 1, \quad \forall j$

$0<\tau, p$

where

- Eq. (15.a) expresses the wear and degradation of the jth component over its lifetime;

- Eq. (15.b) represents how the imperfect maintenance action causes a cumulative fault distribution level;

- Eq. (15.c) is related to the maintenance policy, where $R g_{\text {inf }}$ is the lower reliability threshold of the system.

- Eq. (15.d) expresses that a period of time must exist between preventive maintenance actions.

Remark 6. Note that each $C_{j, \eta}^{*}$ requires different $T_{j}$ value. Moreover, if the multi-component system has non-identical components, the system will potentially have a preventive maintenance action periodicity for each component (e.g. one component of the system can require 20 weeks between preventive maintenances, but another can require 21 weeks, and a third one can require 22 weeks, and so on; nonetheless, it does not make sense to intervene the system each week). Therefore, a next stage of the optimisation process should be the minimisation of the maintenance cost by clustering preventive maintenance actions, which is developed for obtaining the appropriate maintenance plan.

\subsection{Optimal cost by clustering preventive maintenance actions}

The function $C_{j, i}$ describes the maintenance cost for each $j$ th component at an instant $i$ of its lifetime, i.e. $\eta=i$; afterwards, the optimal maintenance $\operatorname{cost} C_{j, i}^{*}$ can be calculated, as a result, a noisy point cloud with locally non-uniform distributions $\left\{C_{j, i}^{*}\right\}$ is generated for every time an instant of the lifetime is analysed for a set of components (see Fig. 5a). Combining the maintenance actions over different components is also known as clustering or opportunistic maintenance. There is a potential cost-saving by implementing an opportunistic maintenance policy for multi-component systems (Wang, 2002). The objective is to group maintenance activities to reduce the maintenance cost. Moreover, grouping of maintenance actions should be considered to find an optimal maintenance policy in order to consider the economic interdependencies between components in a multi-component system. Consequently, the predictive maintenance policy must be based on grouping maintenance activities (Chalabi, Dahane, Beldjilali, \& Neki, 2016; Nicolai \& Dekker, 2008). This has been achieved by implementing cluster analysis, which is discussed in the following lines.

Cluster analysis is the formal study of methods and algorithms for grouping. Clustering is made according to intrinsic characteristics, such as similarity state-rate degradation. Where, given a finite set $\left\{C_{j, i}^{*}\right\}$, there are $K$ groups based on the measurement of similarity, in which similarities between optimal costs in the same group are high while similarities between objects in different groups are low, for $K$ ? J (Jain, 2010). The clusters of preventive actions provide the possibility of grouping maintenance activities in a subset from $\left\{C_{j, i}^{*}\right\}$ to reduce the maintenance cost over $\eta=i$. Each subset is a collection of mutually exclusive groups, the set of groups is expressed as $E=\left\{e_{k}\right\}, \forall e_{k}=\left[\mathbb{T}_{k}, C_{k}^{* *}\right]$ with $k=\{1,2, \ldots, K\}$, which covers the periodicity of all preventive maintenance actions. Finally, a grouping structure $k$ is defined as a subset wherein all activities are jointly executed at $\operatorname{cost}\left\{C_{k}^{* *}\right\}$, which is defined as the optimal maintenance for the group $\left\{\mathbb{T}_{k}\right\}$ (see Fig. 5b). Further on, each optimal cost $\left\{C_{j, i}^{*}\right\}$ is evaluated against its nearest cluster centre to get the optimal periods $C_{k}^{* *}=C_{j, i}^{*}\left(\mathbb{T}_{k}\right), \forall C_{j, i}^{*} \in e_{k}$ (see Fig. $5 \mathrm{c}$ ). 


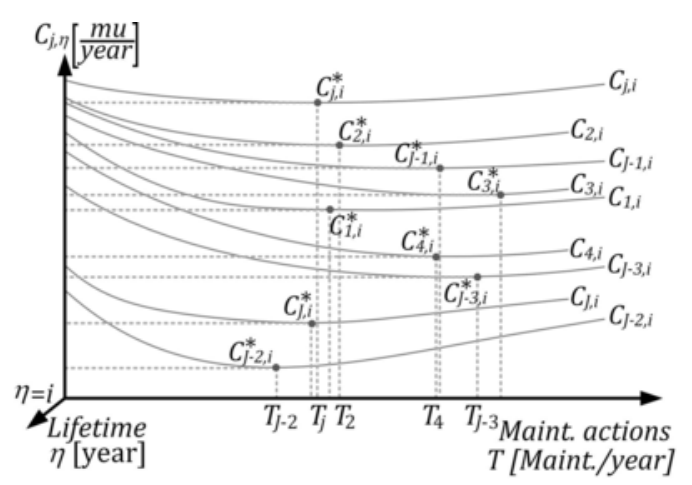

a. Optimal cost $\left\{C_{j i}^{*}\right\}$ in a fixed lifetime, $\eta=i$.



c. Optimal period $\left\{\mathbb{T}_{k}\right\}$ in a fixed lifetime, $\eta=i$.

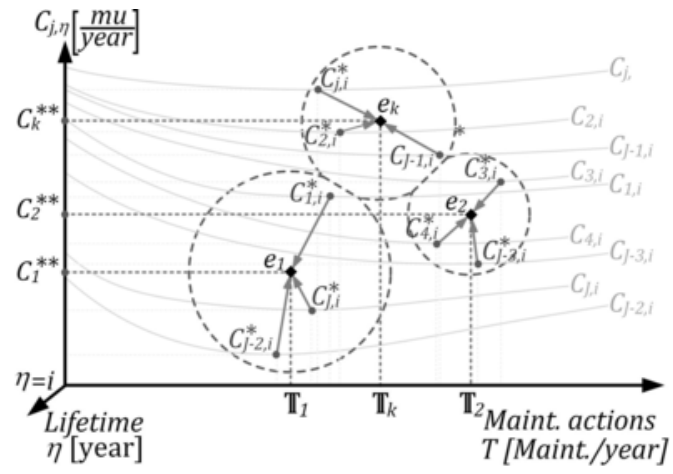

b. Clustering $\left\{\mathcal{C}_{k}^{* * *}\right\}$ in fixed lifetime, $\eta=i$.

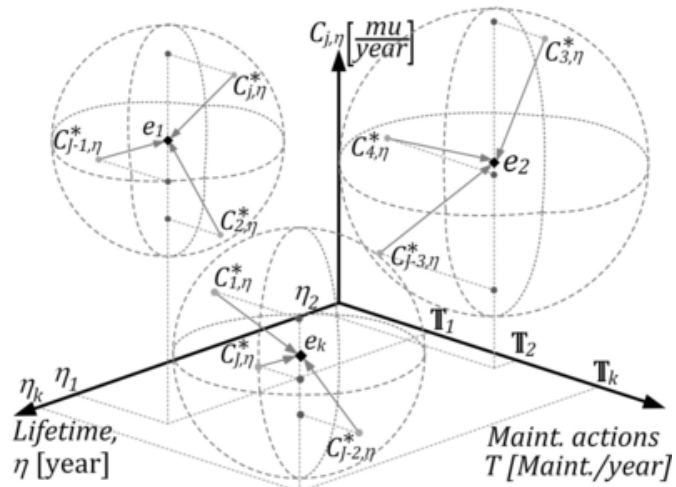

d. Clustering $\left\{C_{k}^{* *}\right\}$ over the lifetime, $\eta$.

Fig. 5. Clustering process of preventive maintenance actions.

There are different clustering methods (Han, Kamber \& Pei, 2011; Kaufman \& Rousseeaw, 2009): (i) partitioning; (ii) hierarchical, (iii) density-based, (iv) grid-based; and (v) their combinations. Partition-based clustering algorithms include the $k$-means method, which is widely used and well-studied in the literature. This work will use $k$-means to group the dataset from optimal costs $\left\{C_{j, \eta}^{*}\right\}$ into $k$ disjoint clusters $\left\{\mathbb{T}_{k}\right\}$. From a finite set $\left\{C_{j, \eta}^{*}\right\}$ to be clustered into a set of $K$ clusters, $k$-means algorithm finds a subset such that the square error between the centre of the cluster and the optimal costs in the cluster is minimised (Jain, 2010; Mahesh-Kumar \& Rama-Mohan-Reddy, 2017). Let $\overline{e_{k}}$ be the Euclidean distance between $\left\{C_{j, i}^{*}\right\}$ and the centre of the subset $\left\{e_{k}\right\}$, the clustering maintenance cost is defined as the squared error distortion in the following objective function

$E=\sum_{j} \arg \min \left\|C_{j, \eta}^{*}-\overline{e_{k}}\right\|^{2}$, with $e_{k}=\left[\mathbb{\pi}_{k}, \eta_{k}, C_{k}^{* *}\right]$

k-means algorithm has two stages: (i) initialisation, wherein the starting set $\left\{e_{k}\right\}$ is defined and (ii) an iterative stage, called Lloyd's algorithm, which consists of two steps: (a) each instance is assigned to its closest $\left\{e_{k}\right\}$ - assignment step, then the set of $\left\{e_{k}\right\}$ is updated - updating step; and (b) a stopping criterion is verified, the most common criterion implies the computation of the error function, Eq. (16), i.e. if the error does not decrease significantly with respect to the previous iteration, the algorithm stops (Capó, Pérez \& Lozano, 2017). Thus, the finite set $\left\{C_{j, \eta}^{*}\right\}$ is evaluated on the nearest $\left\{e_{k}\right\}$ to get $\left\{C_{k}^{* *}\right\}$ as follow

$C_{k}^{* *}=C_{j, \eta}^{*}\left(\mathbb{\mathbb { T }}_{k}, \eta_{k}\right) ; \quad \forall C_{j, \eta}^{*} \in e_{k}$.

The dataset $\left\{C_{k}^{* *}\right\}$ represents the optimal maintenance action cost of the components with a cost-saving by implementing an opportunistic maintenance policy for multi-component systems with economic dependency; $\left\{C_{k}^{* *}\right\}$ varies as the components wear, so the clustering method (Eqs. (16) and (17)) can be directly expanded to the lifetime of the system (see Fig. 5d).

\section{Numerical study}

This section presents an application for passenger-aerial-cable-cars to validate the numerical results. The transport system is similar in design and construction to those used for tourist passenger transport during the winter for winter sports (e.g., Daemyung, Korea; La Clusaz, France; Donovaly, Slovakia), but in this case it is used for massive urban transport, which is different from touristic systems (Mizuma, 2004); therefore, the transport system is subjected to extreme wear-off levels that similar systems do not endure, causing high wear-off ratio (Hoffmann, 2006).

\subsection{Background - urban ropeway transport}

This numerical application considers the fleet of a massive urban transport system with the following characteristics (Martinod et al., 2015): (i) gondola-type aerial cable, (ii) a continuous cycle, (iii) mono-cable (simple ring), and (iv) detachable release-clamp device (see Table 2). The aerial ropeway system is a télécabine-type system, with a pulling cable constantly revolving in one direction. Vehicles are attached and detached when they are entering and travelling through a platform. This feature allows for the vehicles to be set at a regular space interval, and the cable to be continuously circulating along the vehicles (Estepa, et al., 2014). The vehicles that are detached from the hauling rope at the platform are decelerated and carried through a boarding and departing area for passengers at a very slow speed, afterwards they are accelerated to reattach to the hauling rope while moving in between stations. This application example focuses on the maintenance actions for two sets of critical components:

(i) a set of safety components are the detachable grips, these components have the function of clamping (during inter-station trips) and releasing (during transit inside the stations) the vehicle when to 
Table 2

General features of the transport ropeway system.

\begin{tabular}{ll}
\hline Operational parameters & Value \\
\hline Quantity of service days [day/year] & 365.00 \\
Time under rush hour service [h/day] & 4.00 \\
Time under valley rush hour service [h/day] & 16.00 \\
Commercial speed rush hour [m/s] & 5.00 \\
Commercial speed valley hour [m/s] & 3.00 \\
Length of journey (round trip) [km] & 6.00 \\
Nominal quantity of vehicles in service [veh] & 60.00 \\
Quantity of detachable grips in series configuration [unit] & 3.00 \\
Distance between vehicles [m/veh] & 61.67 \\
Quantity of platforms per journey [platform /journey] & 4.00 \\
Wear-off ratio of detachable grips [cycle/platform] & 2.00 \\
Wear-off ratio of tyre conveyors [cycle/veh] & 1.00 \\
Maintenance policy parameters & \\
Cost of preventive maintenance action, $C p$ [mu] & 20.00 \\
Cost of corrective maintenance action, $C c[$ mu] & $10 C p$ \\
Age reduction coefficient (major maintenance), $\alpha_{1}[-]$ & 0.10 \\
Age reduction coefficient (minor maintenance), $\alpha_{2}[-]$ & 0.30 \\
Quantity of minor maintenance per major maintenance, $p[-]$ & 3.00 \\
Lower threshold of the reliability function, $R_{\text {inf }}[\mathrm{cycles}]$ & 0.98 \\
Stochastic index due the quality of maintenance, $\beta[-]$ (uniform & {$[0, \ldots, 1]$} \\
distribution) & {$[1, \ldots, 10]$} \\
Quantity of preventive maintenance actions per year, $T[-]$ & \\
\hline
\end{tabular}

and from the track rope, by providing the clamping force needed to attach the vehicle to the track rope during the journey (Martinod et al., 2015). The detachable grips are a part of the vehicles (there is one of them per gondola). Under normal exploitation conditions, the ropeway operates with all vehicles working, but the system can support up to two missing vehicles, i.e. the system remains in operational conditions with a maximum of two failed detachable grips (parallel configuration), if the system undergoes three or more failed detachable grips, the system must stop -series configuration(Peng, Mo, Xie, \& Levitin, 2013), affecting the service policy. Following the application example, the set of detachable grips reliability is $\left\{R_{d 1}, R_{d 2}, \ldots, R_{d J}\right\}$, with $d J=60$, because the quantity of sets of detachable grip components is equal to the quantity of vehicles.

(ii) another set of components is the tyre conveyors, this device has got the function of the deceleration and acceleration of the vehicles through each platform. The ropeway system requires that every single tyre works; otherwise, the system must stop to fix the tyre, then the tyre conveyor has a series configuration in the system, the set of tyre conveyor reliability, considering the four platforms, is $\left\{R_{c 1}, R_{c 2}, \ldots, R_{c J}\right\}$ with $c J=366$.

Ropeway maintenance managements have adopted a periodic preventive maintenance based on a periodic block-type maintenance policy. These maintenance actions are executed according to a fixed schedule following linearly-spaced periods. Thus, in safety requirements for cableway installations, such as ropeways transport, a periodic preventive maintenance has already been widely introduced as a technical specification within the industry. Directive /9/EC()2000, 2000 provides the technical regulations for passenger ropeway systems (e.g. funicular railways, cable cars, gondolas, chairlifts, and drag lifts). This directive covers the international standard BS/EN-()1709, 2004 that establishes the guidelines for inspections and maintenance.

\subsection{Optimisation of maintenance actions cost to the set of detachable grips and tyre conveyors}

A previous study (Trujillo, 2013) developed an evaluation and analysis focused on components of an urban ropeway transport system. This study was based on Reliability, Maintainability, and Availability (RMA) methodology. The fault probability distribution and the reliability probability functions for the detachable grips and the tyres convey- ors were also measured. This study found the parameters that describe the fault probability distributions, which can be fitted by means of Weibull distributions. The application example assumed that all analysed components $(j=\{\{d 1, \ldots, d J\},\{c 1, \ldots, c J\}\})$ were non-identical components and they had different failure processes $f_{j}$, then the set of reliability function was $\left\{R_{1}, \ldots, R_{J}\right\}$ with $J=d J+c J$. All the dataset is available from the authors of this article; as an example, a sample of the components reliability behaviour is shown in Appendix B, Fig. B.1, where each component has different: (i) cumulative fault probability function; (ii) current cumulative fault level; and (iii) fault level.

The maintenance policy seeks to minimise the cost of the associated activities (Ahmadi et al., 2016; Qiu et al., 2017); then, the degradation during the lifetime of the components are computed by means of five stages: (i) the functions $f_{j}, F_{j}$ and $R_{j}$ are calculated to get the progressive degradation of the components when working under operation conditions, which considers just the corrective maintenance actions, it means a reactive maintenance policy is applied, without preventive maintenance actions; (ii) the effect of the imperfect maintenance action is calculated, varying $T_{j}$, see Appendix B, Fig. B.2; (iii) the degradation of each component is found by the superposition principle, to get the mixed maintenance cost due to the corrective and preventive maintenance actions, see Fig. 6; (iv) the set of minimal maintenance costs $\left\{C_{j, \eta}^{*}\right\}=\min \left(\left\{C_{j, \eta}\right\}\right)$ is calculated, varying $\eta$; and (v) the dataset of minimal maintenance cost $\left\{C_{j, \eta}^{*}\right\}$ is grouped into $K$ sets by k-means.

The maintenance actions and their associated cost are a well-known topic by ropeway maintenance managements. To show the performance of the proposed model a set of simulations are applied to different scenarios, which are being considered in the following two application examples:

(i) maintenance cost by using a periodic block-type preventive maintenance, which is the traditional maintenance policy established by the international regulation. The variables of decision $\left(T, \mathbb{T}_{k}\right)$ have been considered, and combinatory tests were executed based on the lifetime $\eta=\{0, \ldots, 3\}$ [year] and the range $T=\{2, \ldots, 10\}$ [maint. actions/year]. Fig. 7a shows a synthesis of the results, where the cost of the periodic block-type preventive maintenance is clustered through $\mathbb{T}_{k}=\{1, \ldots, K\}$, with $K=5$.

(ii) maintenance cost using an age-based preventive maintenance, which can be used to quantify the effectiveness of the applied current maintenance policy. Fig. $7 \mathrm{~b}$ shows a synthesis of the results, where the cost of the age-based preventive maintenance is clustered through $\mathbb{T}_{k}=\{1, \ldots, K\}$, with $K=5$.

\subsection{The optimal long-term cost maintenance by clustering preventive maintenance actions}

Given a finite set of sampled points from the curve $\left\{e_{k}\right\}$, that represents the opportunistic cost value of the clustered optimal period $\left\{C_{k}^{* *}\right\}$, a parametric method can be applied to find a mathematical expression $g=\mathscr{F}_{h}(u)$, which describes the behaviour of the maintenance cost in relation to the lifetime of the system, i.e. $g$ represents the function cost of the maintenance actions (preventive and corrective as well). The stochastic points $\left\{e_{k}\right\}$ are sampled by following systematically-ordered-patterns, i.e. the data $e_{k}=\left[\mathbb{T}_{k}, \eta_{k}, C_{k}^{* *}\right]$ has connectivity with $e_{k+1}$ (see Fig. 8a). The mathematical expression $g=\mathscr{F}_{h}(u)$ is a piecewise-defined parametric curve with $\mathscr{F}_{h}(u)=\left[\mathbb{\mathbb { T }}_{k}(u), \eta_{k}(u), C_{k}^{* *}(u)\right]$ where the parameter $u$ is one of the many possible ways to parameterise the $h$ th curve $\mathscr{F}_{h}$. The parametric curve $\mathscr{F}_{h}$ was proposed by Bézier, De Casterljeau, and others, and it is expressed as (Ruiz, 2002)

$\mathscr{F}_{h}(u)=\sum k B_{k}(u) e_{k}$,

with 0 ? $u$ ? 1 and $\sum k B_{k}(u)=1 ; B_{k}(u)$ is known as Bernstein polynomial. The $k$ th weight coefficient for the $k$ th point belongs to a subset 

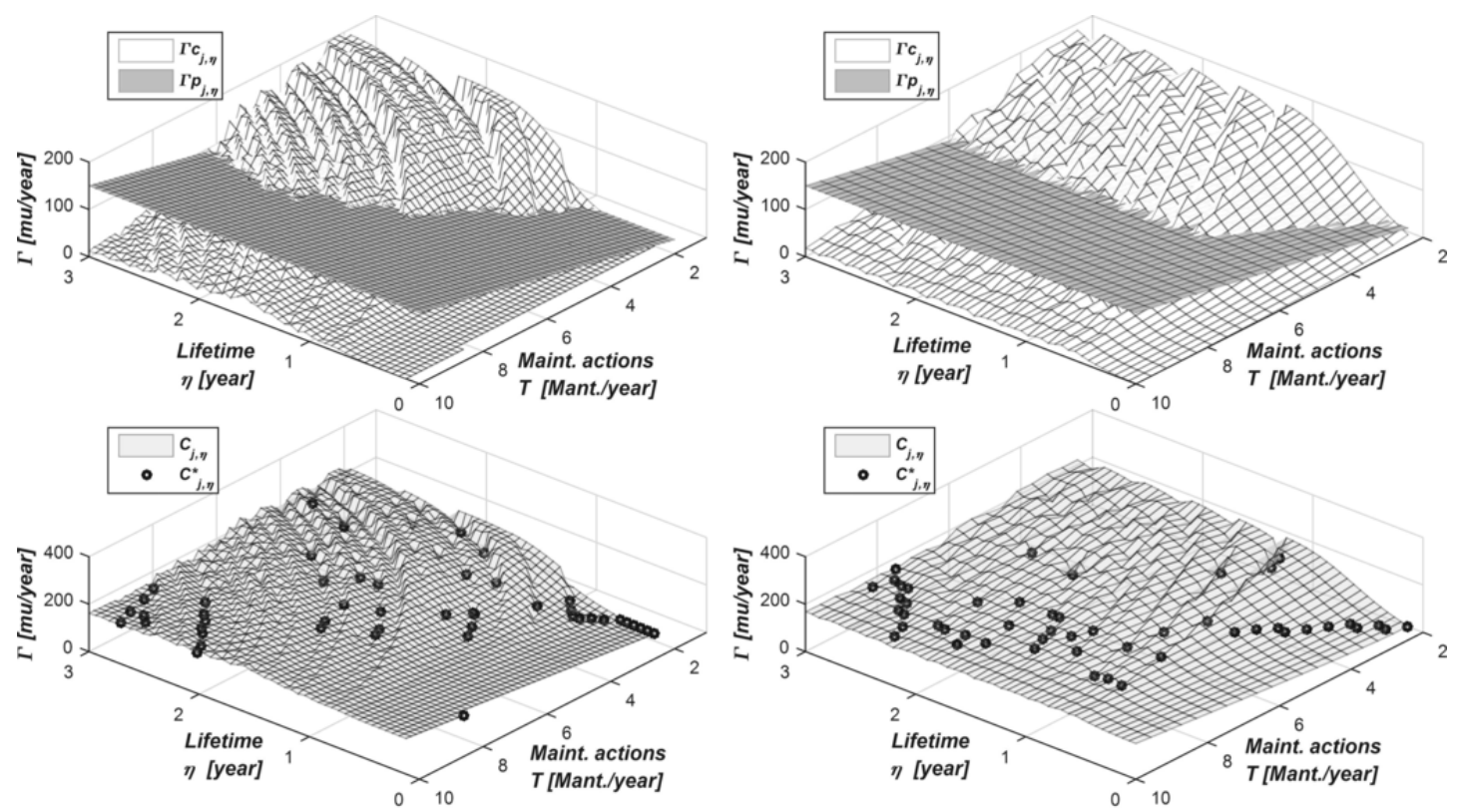

a. Periodic block-type preventive maintenance policy.

Fig. 6. Objective function of the maintenance cost over $\eta$ of the $j$-th component.

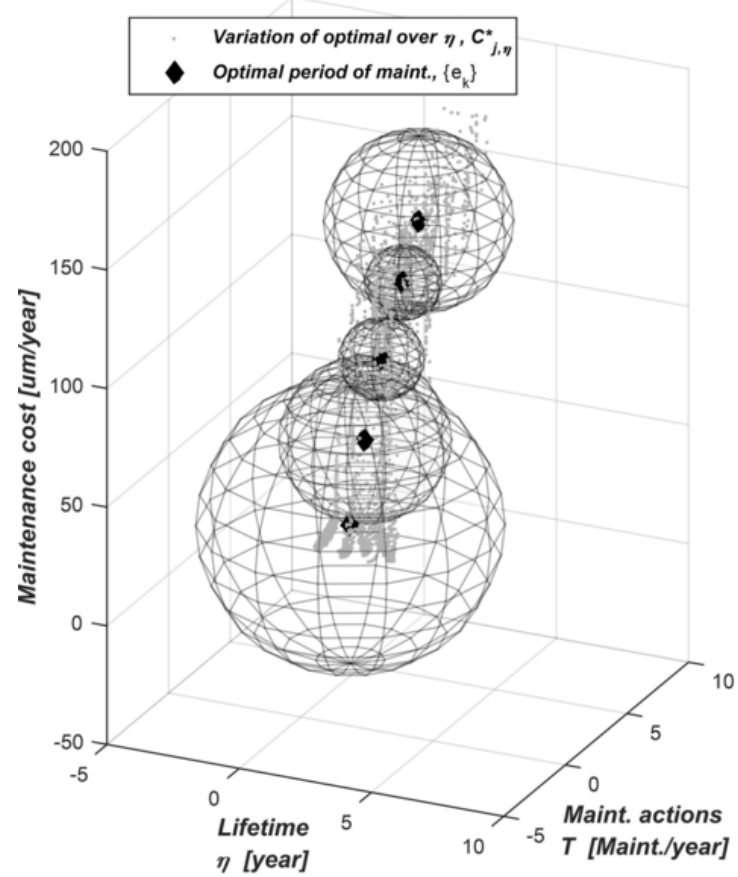

a. Periodic block-type preventive maintenance policy.

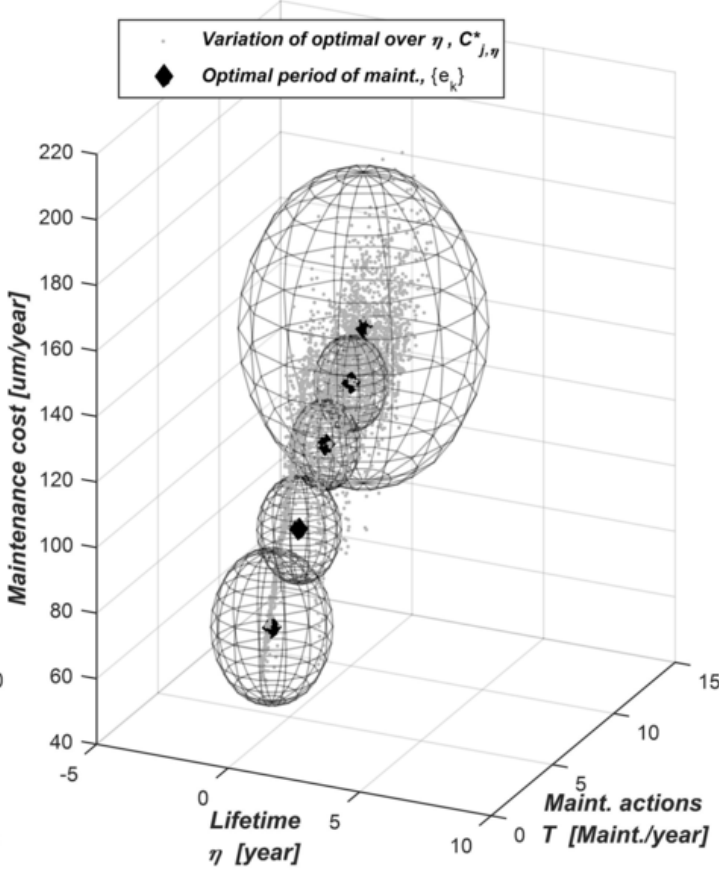

b. Age-based preventive maintenance policy.

Fig. 7. Clustering the optimal cost $\left\{C_{k}^{* *}\right\}$ over the lifetime, $\eta$.

$\left\{e_{k-l}, e_{k}, e_{k+l}\right\}$ where $1 ? l ? K$. One of the Bernstein polynomic is the spline interpolation, which is a piecewise-defined numeric function. The piecewise spline interpolation is appropriate because it yields similar results while interpolating higher degree polynomials and avoids instability caused by the Runge's phenomenon.

From the clustered dataset $\left\{e_{k}\right\}$, it is possible to show the existing relationship between the optimal cost $\left\{\mathrm{C}_{\mathrm{k}}^{* *}\right\}$ and the periodicity of preventive maintenance actions $\left\{\mathbb{T}_{k}\right\}$ which are being applied to the periodic block-type maintenance policy as well as the age-based maintenance policy (see Fig. 8b). A polynomial regression model is obtained, with a correlation coefficient $\sqrt{R^{2}}>0.97$

$$
g=\left[\begin{array}{lll}
-3.64 & 48.97 & -22.23 \\
-3.87 & 57.88 & -63.22
\end{array}\right]\left[\begin{array}{lll}
T^{2} & T & 1
\end{array}\right]^{\mathrm{T}},
$$

The regression model is considered valid given that the $\sqrt{R^{2}}$ value represents the association with the obtained data, which have an acceptable level for the scope of this work.

Remark 7. Note that the maintenance cost of the system relies on the lifetime of the components; therefore, there is an optimal working- 


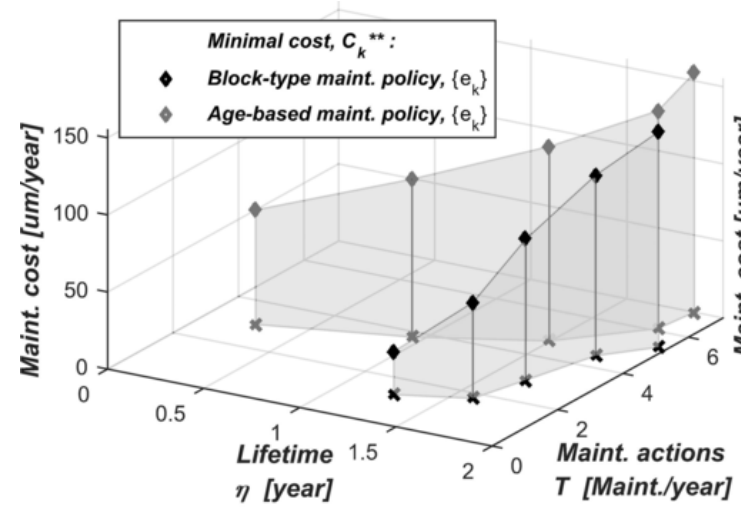

a. Cluster of maintenance actions $\left\{e_{k}\right\}$ over the lifetime, $\eta$.

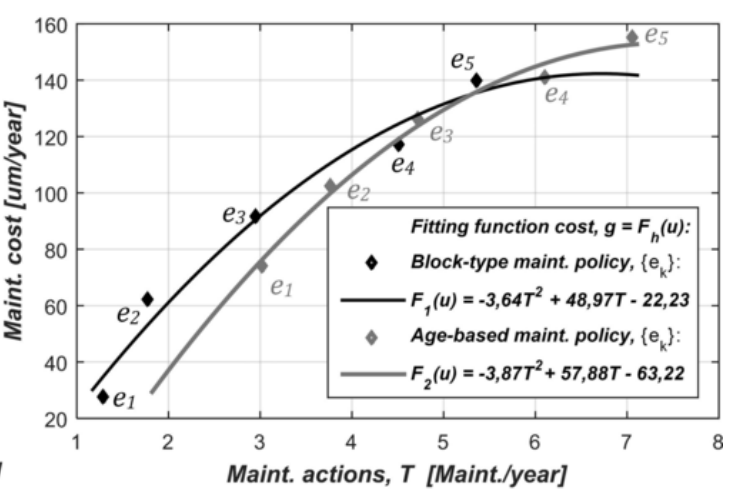

b. Periodicity of maintenance actions.

Fig. 8. Results of clustering the optimal cost $\left\{C_{k}^{* *}\right\}$.

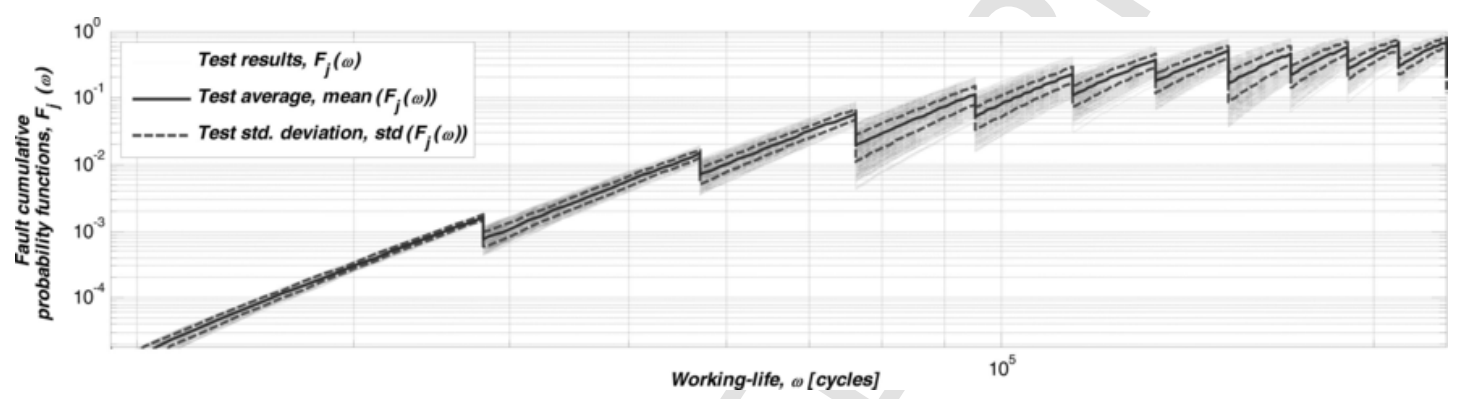

Fig. A.1. Sensitivity tests results.

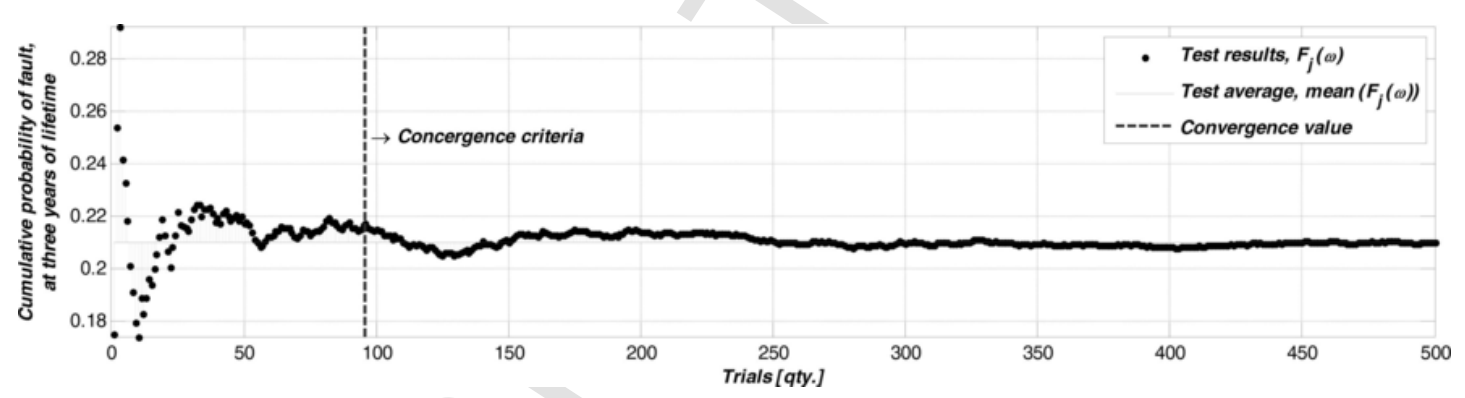

Fig. A.2. Convergence tests result.
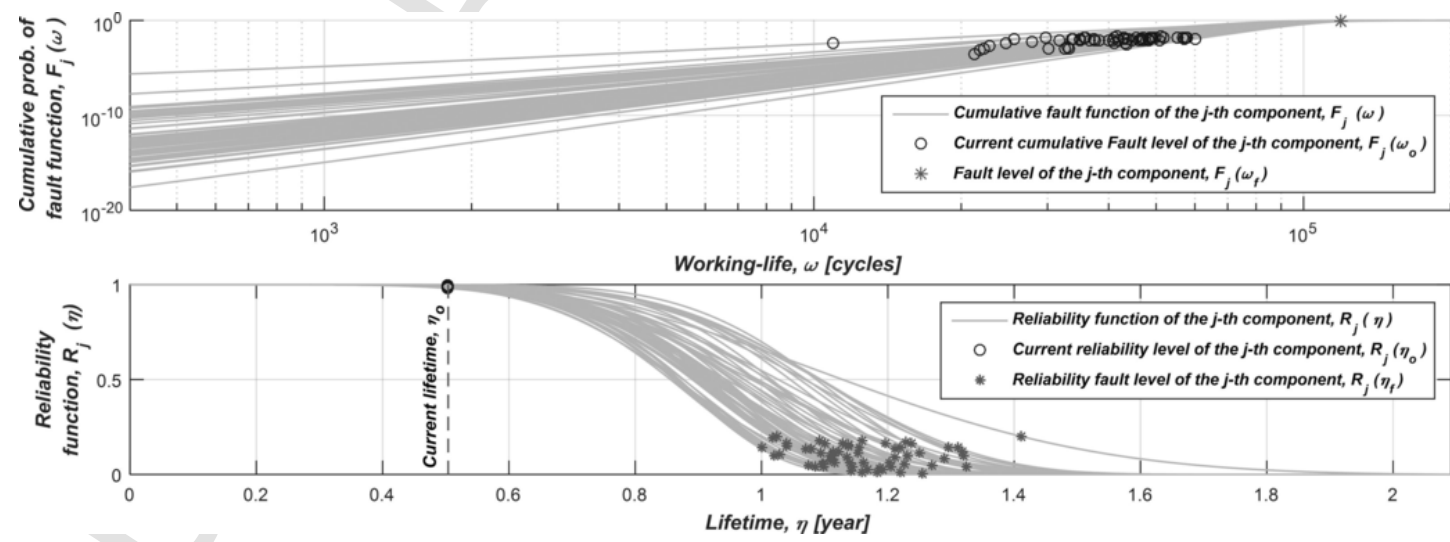

Fig. B.1. Sample of the components reliability behaviour. 

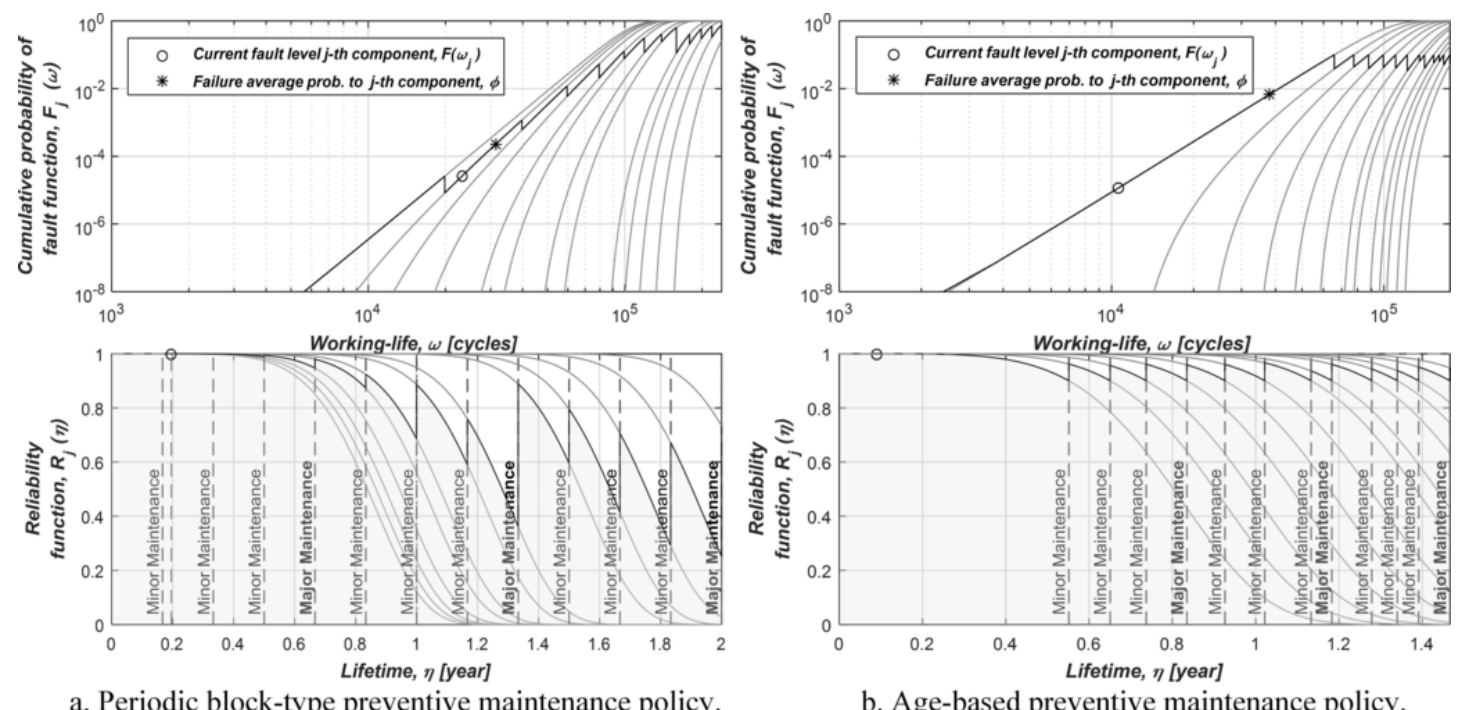

b. Age-based preventive maintenance policy,

Fig. B.2. Preventive imperfect maintenance policies.

life value to switch the maintenance policy which allows the minimal cost (considering the preventive and corrective maintenance actions).

\subsection{Discussion of results from the proposed strategy of maintenance policy compared with the current strategy used}

Ropeways maintenance management have adopted a periodic preventive maintenance based on a periodic block-type maintenance policy, which the maintenance actions are executed according to a fixed schedule based on linearly-spaced periods; therefore, the function cost of the maintenance actions is expressed as $\mathscr{F}_{1}(u)=-3.64 T^{2}+48.97 T-22.23$ (see Fig. $8 \mathrm{~b}$ ).

This work shows that neither periodic block-type maintenance nor an age-based maintenance are necessarily the optimal strategy of maintenance policy over a long time of working-life. The optimal strategy must consider both policies; at the beginning of the working-life, the applied maintenance policy ought to be the age-based, whereas the components of the system undergo wear and degradation, the maintenance policy ought to switch to the periodic block-type; therefore, the function cost of the maintenance actions is $\min \left\{\mathscr{F}_{h}(u)\right\}$, i.e.

$$
\begin{aligned}
g & =\underset{\eta}{\min } \mathscr{F}_{h}(u) \\
& =\left\{\begin{array}{l}
-3.87 T^{2}+57.88 T-63.22 ; \text { with } T \leqslant 5 \\
-3.64 T^{2}+48.97 T-22.23 ; \text { with } T>5
\end{array}\right.
\end{aligned}
$$

Summarising, the proposed maintenance strategy minimises the function cost of the maintenance actions, thus it is an improvement regarding the current strategy used by the ropeway transport systems.

\section{Conclusions}

This article develops a mathematical framework to integrate the optimisation of a dependence-based model with different maintenance policies (periodic block-type policy and age-based policy) using reliability analysis to solve the problem in multi-component systems through minimising the preventive and corrective maintenance costs.

This study has also obtained the optimal maintenance cost by means of cost saving through implementing an opportunistic maintenance policy in multi-component systems with a relationship of stochastic economic dependency. For this purpose, this work was based on two stages: (i) an imperfect preventive maintenance model based on two different maintenance policies (periodic block-type maintenance and age-based maintenance); and (ii) a clustering method for mainte- nance actions in order to decrease the total maintenance cost in complex systems.

This work assumes that a system is composed by multiple sets of components, each set can include the same type of components, but the components are non-identical (e.g. the set of detachable grips are composed by sixty components, but each component has its own working rate variation due to different operating conditions within the system). Furthermore, this article develops a maintenance model, which considers the effects under multiple types of independent degradation processes to each grouped component.

Maintenance managers of transport systems follow the maintenance policy established by the international regulation of passenger aerial cable cars, which considers a single maintenance policy (periodic block-type maintenance) during the whole working-life cycle. This work proves that the appropriate strategy is to consider both policies and to apply the correct one according to the lifetime of the system in order to reach the optimal maintenance cost, i.e. to consider a strategy with an isolated maintenance policy is not the most sensible strategy.

The proposed optimisation model has been performed on a passenger urban aerial ropeway transport system, which consist of a set of 426 components, wherein the problem was solved and the results were obtained using an acceptable time computing resource ( $1 \mathrm{~h}$ and $30 \mathrm{~min}$. approx.). Note that the optimisation model was numerically solved using affordable resources: (i) the algorithms was developed in a high-level programming language - MATLAB; and (ii) the data was run on a processor Intel Core i7 CPU @ 2.93 GHz 3.07 GHz, 64 bits, 16 GB RAM.

Future research will focus on the following two major aspects: (i) it is possible to propose other study, in which broaden different relationships of the cost-efficiency function for maintenance actions - polynomial functions, hyperbolic functions, exponential function, etc., where an analysis of the system characteristic and its implications is considered; this work only has considered a linear function for the relationship of maintenance costs $\left(C_{1}\right.$ and $\left.C_{2}\right)$ and the efficiency of its maintenance action; (ii) $\beta_{j, \eta}$ could be estimated through artificial intelligence methods (e.g. fuzzy logic) considering the maintenance manager could quantify these operative actions according to the planning and scheduling because in this work $\beta_{j, \eta}$ was defined as uncertainty factor given its stochastic hazard rate relation to human and technical uncertainty; and (iii) it is possible to propose a further analysis that includes the social and environmental costs, so an approximation to a sustainability model is established; this work only provides an analysis from the company profit perspective. 


\section{Appendix A. Results of validation tests of the numerical model.}

\section{Appendix B. Results of a typical jth component}

\section{Appendix . Supplementary data}

Supplementary data associated with this article can be found, in the online version, at https://doi.org/10.1016/j.cie.2018.07.019.

\section{References}

Ahmad, R., Kamaruddin, S., 2012. An overview of time-based and condition-based maintenance in industrial application. Computers \& Industrial Engineering 63 (1), 135-149.

Ahmadi, A., Soleimanmeigouni, I., Block, J., Letot, C., 2016. Optimum failure management strategy for periodically inspected units with imperfect maintenance. IFAC 49 (12), 799-804.

Briš, R., Byczanski, P., 2013. Effective computing algorithm for maintenance optimization of highly reliable system. Reliability Engineering \& System Safety 109, 77-85.

Briš, R., Byczanski, P., Goňo, R., Rusek, S., 2017. Discrete maintenance optimization of complex multi-component systems. Reliability Engineering \& System Safety 168, $80-89$.

BS/EN-1709, 2004. Safety requirements for cableways for cableway installations designed to carry persons. Precommissioning inspection, maintenance and operational inspection and checks. British Standards Institute, 3-24.

Capó, M., Pérez, A., Lozano, J.A., 2017. An efficient approximation to the K-means clustering for massive data. Knowledge-Based Systems 117, 56-69.

Chalabi, N., Dahane, M., Beldjilali, B., Neki, A., 2016. Optimisation of preventive maintenance grouping strategy for multi-component series systems: Particle swarm based approach. Computers \& Industrial Engineering 102, 440-451.

Chelbi, A., Ait-Kadi, D., 2001. Spare provisioning strategy for preventively replaced systems subjected to random failure. International Journal of Production Economics 74, $183-189$.

Cheng, G.Q., Zhou, B.H., Li, L., 2017. Joint optimization of lot sizing and condition-based maintenance for multi-component production systems. Computers \& Industrial Engineering $110,538-549$.

Cho, D., Parlar, M., 1991. A survey of maintenance models for multi-unit systems. European Journal of Operational Research 51, 1-23.

Directive 2000/9/EC. Relating to cableway installations designed to carry persons. Eurpean Parliament Council of Europe Union. pp. 21-48.

Do, P., Vu, H.C., Barros, A., Bérenguer, C., 2015. Maintenance grouping for multi-component systems with availability constraints and limited maintenance teams. Reliability Engineering \& System Safety 142, 56-67.

Doyen, L., Gaudoin, O., 2004. Classes of imperfect repair models based on reduction of failure intensity or virtual age. Reliability Engineering \& System Safety 84 (1), 45-56.

Estepa, D., Martinod, R.M., Paris, C.E., Pineda, F.A., Restrepo, J.L., Castañeda, Leonel F., Mejía, Gustavo A., 2014. Operating conditions effect over the coupling strength for urban aerial ropeways. Transport Problems 9 (3), 5-14.

Gustavsson, E., Patriksson, M., Strömberg, A.B., Wojciechowski, A., Önnheim, M., 2014. Preventive maintenance scheduling of multi-component systems with interval costs. Computers \& Industrial Engineering 76, 390-400.

Han, J., Kamber, M., Pei, J., 2011. Data mining: Concepts and techniques. Morgan Kaufmann.

Iung, B., Do, P., Levrat, E., Voisin, A., 2016. Opportunistic maintenance based on multi-dependent components of manufacturing system. CIRP Annals 65 (1), 401-404.

Jain, A.K., 2010. Data clustering: 50 years beyond K-means. Pattern Recognition Letters $31,651-666$
Kaufman, L., Rousseeaw, P.J., 2009. Finding groups in data: An introduction to cluster analysis. John Wiley \& Sons.

Khatab, A., Ait-Kadi, D., Rezg, N., 2013. Availability optimisation for stochastic degrading systems under imperfect preventive maintenance. International Journal of Production Research 52 (14), 4132-4141.

Kijima, M., 1989. Some results for repairable systems with general repair. Journal of Applied probability 26 (1), 89-102.

Liu, B., Xu, Z., Xie, M., Kuo, W., 2014. A value-based preventive maintenance policy for multi-component system with continuously degrading components. Reliability Engineering \& System Safety 132, 83-89.

Liu, H., Yeh, R.H., Cai, B., 2017. Reliability modeling for dependent competing failure processes of damage self-healing systems. Computers \& Industrial Engineering 105, $55-62$.

Mahesh-Kumar, K., Rama-Mohan-Reddy, A., 2017. An efficient k-Means clustering filtering algorithm using density based initial cluster centers. Information Sciences 418, 286-301.

Martinod, R.M., Estepa, D., Paris, C.E., Trujillo, A., Pineda, F.A., Castañeda, Leonel F. Restrepo, Jorge, 2015. Journey safety assessment to urban aerial ropeways transport systems based on continuous inspection during operation. Journal of Transportation Safety \& Security 7 (4), 279-290.

Martinod, R. M., Bistorin, O., \& Rezg, N. (2018). Combined optimisation of operation and maintenance policies applied to urban ropeway transport systems. Transportation Science. research paper TS-2017-0234, submitted 2017 (in preparation).

Nicolai, R.P., Dekker, R., 2008. Optimal maintenance of multi-component systems: A review. In: Kobbacy, K.A.H., Prabhakar, D.N. (Eds.), Complex system maintenance handbook. Springer, London, pp. 263-286.

Peng, R., Mo, H., Xie, M., Levitin, G., 2013. Optimal structure of multi-state systems with multi-fault coverage. Reliability Engineering \& System Safety 119, 18-25.

Peng, H., Zhu, Q., 2017. Approximate evaluation of average downtime under an integrated approach of opportunistic maintenance for multi-component systems. Computers \& Industrial Engineering 109, 335-346.

Pham, H., Wang, H., 1996. Imperfect maintenance. European Journal of Operational Research 94 (3), 425-438.

Qiu, Q., Cui, L., Shen, J., Yang, L., 2017. Optimal maintenance policy considering maintenance errors for systems operating under performance-based contracts. Computers \& Industrial Engineering 112, 147-155.

Ruiz, O. E. (2002). Understanding CAD/CAM/CG. ASME Code GT-006.

Schutz, J., Rezg, N., 2013. Maintenance strategy for leased equipment. Computers \& Industrial Engineering 66, 593-600.

Tian, Z., Liao, H., 2011. Condition based maintenance optimization for multi-componen systems using proportional hazards model. Reliability Engineering \& System Safety 96, 581-589.

Trujillo, A., 2013. Impacto esperado en indicadores de desempeño con la implementación del SPD-Cable en la Línea J del Metro de Medellín. MSc thesis Universidad EAFIT.

Van Horenbeek, A., Pintelon, L., 2013. A dynamic predictive maintenance policy for complex multi-component systems. Reliability Engineering \& System Safety 120, 39-50.

Wang, H., 2002. A survey of maintenance policies of deteriorating systems. European Journal of Operational Research 139 (3), 469-489.

Wang, I.L., Tsai, Y.C.J., Li, F., 2011. A network flow model for clustering segments and minimizing total maintenance and rehabilitation cost. Computers \& Industrial Engineering 60, 593-601.

Yang, Z.M., Djurdjanovic, D., Ni, J., 2008. Maintenance scheduling in manufacturing systems based on predicted machine degradation. Journal of Intelligent Manufacturing 19, 87-98.

Yang, L., Ma, X., Peng, R., Zhai, Q., Zhao, Y., 2017. A preventive maintenance model based on dependent two-stage deterioration and external shocks. Reliability Engineering \& System Safety 160, 201-211.

Yang, L., Zhao, Y., Peng, R., Ma, X., 2018. Hybrid preventive maintenance of competing failures under random environment. Reliability Engineering \& System Safety 174, $130-140$.

Zhou, X., Huang, K., Xi, L., Lee, J., 2015. Preventive maintenance modeling for multi-component systems with considering stochastic failures and disassembly sequence. Reliability Engineering \& System Safety 142, 231-237. 